\title{
The Status of Implementation of Science Practical Works in Science Teaching -Learning Processes in Some Selected Secondary Schools of Bale Zone, Oromia
}

\author{
Bezabih Wondimu Kibret, $(\mathrm{PhD})^{*}$ \\ Department of Educational Planning and Management, College of Education, Madda Walabu University \\ Hussen Adem \\ Curriculum and teachers professional development studies, Bale-Robe/Ethiopia
}

\begin{abstract}
The purpose of study was to investigate the status of implementation of science practical works in science teaching -learning processes in some selected secondary schools of Bale Zone, Oromia. To address the purpose of this study, mixed research methods were used, and the concurrent triangulation research design was followed to undertake study. Both primary and secondary sources of data were used. To approach these data, both probability and non-probability sampling techniques were used, mainly simple probability sampling technique, stratified probability sampling technique, and purposive non probability sampling techniques were used. Questionnaires and interview were used as data collection tools. After collecting relevant data both quantitative and qualitative data analysis techniques were used for analyze of data. Analysis was done by means of descriptive statistics like frequency distribution, percentage, mean and standard deviation; and, inferential statistics like t-test were employed. The findings of the study showed that the status of implementation of practical work in science in study areas was very low and insufficient. Based on the findings of the study, special attention should be given from government, school management, teachers, communities and other stakeholders to improve quality of science practical work in the schools.
\end{abstract}

Keywords: Status, Practical work, Implementation, Teaching and Learning

DOI: $10.7176 /$ RHSS/10-1-04

Publication date: January $31^{\text {st }} 2020$

\section{Introduction}

Education is a key investment in any country with enormous social and economic benefits accruing from it. Adding, the development of any country is mainly determined by the level and growth of its human capital. It is, therefore, important that every child, whether in rural or urban community, equally benefits from quality basic education in order to promote social, political and economic development of the country (MoE, 2004).

The word "science" probably brings to mind many different pictures: white laboratory coats and microscopes, an astronomer peering through a telescope, a naturalist in the rainforest, Einstein's equations scribbled on a chalkboard, the launch of the space shuttle, bubbling beakers. All of those images reflect some aspect of science, but none of them provides a full picture because science has so many facets: Science is both a body of knowledge and a process. In school, science may sometimes seem like a collection of isolated and static facts listed in a textbook, but that's only a small part of the story. Just as importantly, science is also a process of discovery that allows us to link isolated facts into coherent and comprehensive things (Parawira, 2009).

Science is a way of discovering what's in the universe and how those things work today, how they worked in the past, and how they are likely to work in the future. Scientists are motivated by the thrill of seeing or figuring out something that no one has before. Science is useful. The knowledge generated by science is powerful and reliable. It can be used to develop new technologies, treat diseases, and deal with many other sorts of problems.

Practical work is essentially embodied in the epistemological view that realizes science as discovery learning that is based on an empiricist view. Such a view stipulates that all knowledge of the world is inert and arises from observations and thought processes. In the laboratory, it is necessary to keep various scientific instruments and chemicals in safe and secure conditions, as without them, it is very difficult to carry out any kind of experiment in any way. If schools consist of well-equipped and properly arranged laboratories pupils get motivated to take active part in the experimental work thus laboratory is a congenial kind of atmosphere, which stimulates the interest of students towards practical work. The STEM subjects are ways of knowing and thinking about the natural and physical world. Observing, measuring, and inferring, classifying, predicting and communicating are some of the skills fundamental to STEM education (Parawira, 2009).

Effective practical activities should enable students to build a bridge between what they can see and handle (hands-on), and the scientific ideas that account for their observations (minds-on). In order to practical work to be effective in producing meaningful learning, the teachers should develop activities that engage the learners in 
scientific investigations which focus their minds on the activity and its outcome (Motswiri ,2004). However, classroom practices in most secondary school science education lessons are characterized by chalk-and-talk and little practical work. Some science educators argue that practical work should involve learner-centered learning environment which engage students in knowledge construction as opposed to teacher-center environment which involves information absorption (Gurney, 2008).

\section{Statement of the Problem}

Practical activities have a long distinctive and central role in the science curriculum. More specifically, science practical works have the potential to develop students' abilities and skills such as: posing scientifically oriented questions forming hypotheses, designing and conducting scientific investigations, formulating and revising scientific explanations, and communicating and defending scientific arguments. However, recent study in Ethiopia indicated that students beginning from lower grades have serious knowledge deficits in science and mathematics; which signifies that the quality of science education in primary and secondary schools, which is critical foundations for latter educational development, is at crisis.

Science education should be regarded as "education through science" rather than "science through education" (Holbrook and Rannikmae, 2007). This shows the Importance of practical implementation of practical science which is the focus of the current study. Literature reports that very few studies on the practical implementation of practical Chemistry have been conducted in Ethiopia (Kiflu, 2015). Kiflu (2015) focused on imperative to raise some questions related to the 70:30 professional mix proposed by MoE (2011). How it is possible to place $70 \%$ of preparatory graduates to higher learning institution in science stream where students have low achievement in science subject. For him, there is gap between theory and practices, which in turn needs further investigation. In addition, to the best knowledge of researcher there is a few studies in this regards, Thus, study tends to investigate the status of implementation of practical work in science teaching-learning processes in some selected secondary schools of Bale zone, Oromia.

\section{Objectives of the study}

GENERAL OBJECTIVE OF THE STUDY

The general objective of this study was investigate the status of implementation of practical work in science teaching-learning processes in some selected secondary schools of Bale zone, Oromia.

\section{Specific objectives of the study}

The following specific objectives are derived from general objectives and help to guide the study.

1. To assess the status of practical work implementation in science teaching in secondary schools of Bale zone, Oromia

2. To identify the lesson to be learned in a implementing the practical work in science teaching in selected secondary schools of Bale zone, Oromia.

3. To identify the attitudes of teachers, students, and school principal towards practical work in science teaching in selected secondary schools of Bale zone, Oromia.

4. To indicate the factors affecting the implementation of practical work in science teaching, in secondary school of Bale Zone, Oromia .

\section{Delimitation of the study}

The main purpose of this study investigate the status of implementation of practical work in science teachinglearning processes in some selected secondary schools of Bale zone, Oromia. Content wise, the status, issues and challenges of towards implementation of practical work were taken as the subjects of the study. To this end, the study tends to assess and address the status of practical work implementation in science teaching learning and constraints of practical work in selected secondary schools of Bale Zone, Oromia. Furthermore; the attitudes of teachers, students and school directors towards implementation of practical work in science teaching learning was also the focuses of this study.

\section{Research method and design Research paradigm}

Pragmatism as paradigm was used for investigate the status of implementation of practical work in science teaching-learning processes in some selected secondary schools of Bale zone, Oromia. Pragmatism was used as theory that proves its self-more successful in predicting and controlling our world than its rivals can be considered to be nearer the truth. According to Austin (, 2016), Pragmatic combines both post- positivist and interpretive within a single research. Pragmatism research philosophy can integrate more than research approaches and research strategies within the same study. 


\section{Research methods}

Mixed research methods (both quantitative and qualitative research methods) were used. The basic assumption for using this methods was to provide better understanding of the research problem and answer the research questions than any other methods.

As quantitative research methods tries to quantify the problem and understand how prevalent it is by looking for the projectable results to a larger population, it is used since it involves collecting numerical data. It is fast and easier to gather, analyze, and interpret to understand the research problem.

In addition, a qualitative research method was also used. Because it is not involves the numerical value that would be expressed in numbers. More specifically, concurrent or parallel triangulation research design was used to realize the purpose of the study. Where collection and analysis of quantitative and qualitative data is take place at the same time to best understating of the research problem .so the researcher used concurrent triangulation which the quantitative dominated supplemented with qualitative method (QUAN + qual).

\section{Population of the study}

The populations of the study are 57 secondary schools in Bale zone. Oromia. The total number of teachers in secondary schools are 1063, 57 school director's ,32 vice school director's ,20 supervisor's Researcher and 23152 students .Among these ten secondary schools of Bale zone namely;- Barbare Harewa, Harodumal, Maliyu, Goro, Galema, Robe, Goba, Jibri, Salka, and Hisu secondary schools. Were used as a sample of study of this school's 267 students, 75 teachers, 10 school directors and 13 vice school directors and 10 science laboratory technicians were selected and used sample of study .

Table 1. Population to sample percentage

\begin{tabular}{|c|c|c|c|c|c|c|c|c|c|c|}
\hline \multirow{2}{*}{\multicolumn{2}{|c|}{$\begin{array}{l}\text { No } \\
\text { Nameof school }\end{array}$}} & \multirow{2}{*}{$\begin{array}{l}\text { Student } \\
\text { Population } \\
\end{array}$} & \multicolumn{5}{|c|}{ Teachers } & \multirow[t]{2}{*}{ Lab.tech } & \multirow[t]{2}{*}{$\begin{array}{l}\text { v/prin } \\
\text { cipal }\end{array}$} & \multirow[t]{2}{*}{ principal } \\
\hline & & & Sample & $\%$ & Population & Sample & $\%$ & & & \\
\hline 1 & $\begin{array}{l}\text { Barbare } \\
\text { harewa }\end{array}$ & 521 & 16 & 4 & 9 & 8 & 88 & 1 & 1 & 1 \\
\hline 2 & Harodumal & 715 & 27 & 4 & 9 & 8 & 88 & 1 & 1 & 1 \\
\hline 3 & Goro & 685 & 27 & 4 & 10 & 7 & 70 & 1 & 1 & 1 \\
\hline 4 & Meliyuo & 620 & 25 & 4 & 10 & 8 & 80 & 1 & 1 & 1 \\
\hline 5 & Selka & 417 & 17 & 4 & 8 & 7 & 87 & 1 & 1 & 1 \\
\hline 6 & Hisu & 513 & 18 & 4 & 9 & 8 & 88 & 1 & 1 & 1 \\
\hline 7 & Galema & 1035 & 47 & 4 & 10 & 7 & 70 & 1 & 2 & 1 \\
\hline 8 & Robe & 1190 & 44 & 4 & 10 & 8 & 80 & 1 & 2 & 1 \\
\hline 9 & Goba & 1220 & 46 & 4 & 10 & 8 & 80 & 1 & 2 & 1 \\
\hline & Jibri & 250 & 16 & 4 & 6 & 6 & 100 & 1 & 1 & 1 \\
\hline & Total & 8215 & 267 & 3.7 & 91 & 75 & 82.4 & 10 & 13 & 10 \\
\hline
\end{tabular}

\section{Sample and sampling techniques}

The population for this study is secondary schools students, science teachers, laboratory technicians, school principals, department heads and Woreda educational expert in Bale zone. Of total 57 secondary schools, ten secondary schools was selected by stratified random sampling technique and purposive non-random sampling technique, since students and teachers are not equal size in sample schools. Hence, the study employs proportional techniques will be employed. To this end, the formula and model developed by Yemane (1967) was used to get the sample size used for the study.To this effect by applying the formula ,the sample size was calculated and found out to be 381 . That is $n=N / 1+N(e) 2$ where $n$ is sample size e is tolerable error at $95 \%$.

\section{Source of data}

In this study, both primary and secondary sources of data were used. The primary data sources was collected from laboratory technician principal, vice principal, department head, teachers and students. Whereas, secondary sources were collected from internal reports, manuals and check list of laboratory.

\section{Data collection tools}

To collect sufficient and rich data a variety of instruments, such as questionnaires and interview were used. Questionnaires was prepared and dispatched to science teachers and secondary students. The interview of the participants were integrated and triangulated to enrich and elaborate the quantitative data gathered though questionnaire, during the analysis of data. 


\section{Method of data analysis}

In accordance with the data types, quantitative and qualitative data analyses were employed. Accordingly, the quantitative data was analyzed by using descriptive statistical tools like frequency distribution, percentage and mean which in turn supported by computer Microsoft excel program and Statistical Package for Social Science (SPSS), whereas qualitative data analysis will be analyzed, by direct quotation, paraphrasing, and narration of the review of the respondents.

\section{Analysis, interpretation and discussion}

In this section, the analysis of the quantitative and qualitative data collected from sample population (students of grade 9 and 10, secondary school science teachers, laboratory technicians, principals and educational experts from distinct and zones, and document analysis) are presented and interpreted.

The gathered data are analyzed using tables followed by detailed discussions and showing the statistical relationship using the appropriate parameter. Related questions are analyzed together for the sake of removing redundancy and saving time. Responses collected from lab technicians, school principals and educational experts are incorporated to substantiate the data obtained from the students and teachers. Accordingly, presentation, analysis and interpretation of data were presented here under.

1. Students and Teachers response on the status of implementation of practical works in teaching learning process secondary schools

Table 2. Analysis of student and teachers' response on organization and facilities of science Laboratories.

\begin{tabular}{|c|c|c|c|c|c|c|c|c|c|}
\hline \multirow[t]{2}{*}{ No } & \multirow[t]{2}{*}{ Items of question } & \multirow[t]{2}{*}{$\mathbf{N}$} & \multicolumn{2}{|l|}{$\mathbf{A}$} & \multicolumn{2}{|c|}{ UD } & \multicolumn{2}{|l|}{ DA } & \multirow[t]{2}{*}{ MEAN } \\
\hline & & & $\mathrm{f}$ & $\%$ & $f$ & $\%$ & $\mathrm{f}$ & $\%$ & \\
\hline \multirow[t]{2}{*}{1} & Learning science practically supported & $\mathrm{T}=75$ & 70 & 93.33 & 0 & 0 & 5 & 6.66 & 3.56 \\
\hline & students learning & $S=267$ & 175 & 65.5 & 45 & 16.85 & 47 & 17.6 & \\
\hline \multirow[t]{2}{*}{2} & Science teachers of secondary schools give & $\mathrm{T}$ & 20 & 26.66 & 5 & 6.66 & 50 & 66.66 & 2.77 \\
\hline & $\begin{array}{l}\text { and encourage students to actively } \\
\text { participate in laboratory activities }\end{array}$ & S & 87 & 32.58 & 45 & 16.85 & 135 & 50.56 & \\
\hline \multirow[t]{2}{*}{3} & Teachers have the sufficient skill, & $\mathrm{T}$ & 3 & 4 & 13 & 17.33 & 59 & 78.66 & 2.66 \\
\hline & $\begin{array}{l}\text { experience and professional responsibility } \\
\text { for conducting lab activities to promote your } \\
\text { understanding of science knowledge }\end{array}$ & $\mathrm{S}$ & 79 & 29.58 & 35 & 13.10 & 153 & 57.30 & \\
\hline \multirow[t]{2}{*}{4} & Practical activities should carry a certain & $\mathrm{T}$ & 43 & 16.1 & 93 & 34.8 & 121 & 45.3 & 3.14 \\
\hline & $\begin{array}{l}\text { amount of percentage from the total } \\
\text { score/mark }\end{array}$ & $\mathrm{S}$ & 125 & 46.81 & 43 & 16.10 & 99 & 37.07 & \\
\hline \multirow[t]{2}{*}{5} & $\begin{array}{l}\text { Demonstration of experiments by the } \\
\text { teachers during teaching science in your } \\
\text { school }\end{array}$ & $\mathrm{T}$ & 31 & 41.3 & 6 & 8 & 38 & 50.66 & 2.4 \\
\hline & & $\mathrm{S}$ & 27 & 10.11 & 24 & 8.98 & 216 & 80.89 & 2.912 \\
\hline
\end{tabular}

$\mathrm{T}=$ Teachers $\mathrm{S}=$ Students

As can be shown in table 2 item 1,70(93.3)\%) of the teachers and 175(65.5\%) students agreed that Learning science practically supported students learning. $0(0 \%)$ and $45(16.5 \%)$ of teachers and students respondents replied on undecided respectively. But $5(6.66 \%)$ of teachers and $47(17.5 \%)$ of students disagreed the learning science practical support. The overall mean score 3.56 is between the levels of agree and majority of respondents support the learning science practical support, implying that learning science practically can support student learning.

As can be shown in table 2 item 2, 20(26.66)\%) of the teachers and 87(32.58\%) students agreed that Science teachers of secondary schools give attention and emphasis to practical activities and encourage students to actively participate in laboratory activities. 5(6.66\%) and $45(16.85 \%)$ of teachers and students respondents replied on undecided respectively. But $50(66.66 \%)$ of teachers and $135(50.56 \%)$ of students disagreed that science teachers of secondary schools give attention and emphasis to practical activities and encourage students to actively participate in laboratory activities. The overall mean score 2.77 is between the levels of undecided and majority of respondents disagree science teachers of secondary schools give attention and encourage students toward to practical activities. Thus, from this analysis it is possible to conclude that majority of respondents $50(66.66 \%)$ and $135(50.56 \%$ ) of them replied disagree with mean valve 2.77 , implying that science teachers of secondary schools not give attention and emphasis to practical activities and encourage students to actively participate in laboratory activities

As can be shown in table 2 item 3,3(4)\%) of the teachers and $79(29.58 \%)$ students agreed that teachers have the sufficient skill, experience and professional responsibility for conducting lab activities to promote 
students understanding of science knowledge. 13(17.33\%) and 35(13.10\%) of teachers and students respondents replied on undecided teachers and students respectively. But $59(78.66 \%)$ of teachers and 153(57.30\%) of students disagreed that teachers have the sufficient skill, experience and professional responsibility for conducting lab activities to promote students understanding of science knowledge. The overall mean of the respondents score 2.66 is between the levels of disagreement. Thus, from this analysis it is possible to conclude that majority of teachers and students respondents $59(78.66 \%)$ and $153(57.30 \%)$ respectively replied disagree with the mean valve of 2.66, implying that teachers have not the sufficient skill, experience and professional responsibility for conducting lab activities to promote students understanding of science knowledge.

As can be shown in table 2 item 4, 43(57.33\%) of the teachers and 125(46.81\%) students agreed that practical activities should carry a certain amount of percentage from the total score/mark. 14(18.66\%) and $43(16.10 \%)$ of teachers and students respondents replied on undecided respectively. But $18(24 \%)$ of teachers and $99(37.07 \%)$ of students disagreed that practical activities should carry a certain amount of percentage from the total score/mark. The overall mean score 3.14 is between the levels of agreement. Thus, from this analysis it is possible to conclude that majority of respondent $125(46.81 \%)$ and $43(57.33 \%)$ teachers and students respectively replied agree with mean valve of 3.14, implying that practical activities should carry a certain amount of percentage from the total score/mark.

As can be shown in table 2 item 5, 31(41.3\%) of the teachers and 27(10.11\%) students agreed that demonstration of experiments by the teachers during teaching science in school. $6(8 \%)$ and $24(8.98 \%)$ of teacher and student respondents replied on undecided respectively. But $38(50.66 \%)$ of teachers and 216(80.89\%) of students disagreed that demonstration of experiments by the teachers during teaching science in school. The overall mean of respondents showed 2.43 is between the levels of undecided. Thus, from this analysis it is possible to concluded that majority of respondents $38(50.66 \%)$ and $216(80.89 \%)$ teachers and students respectively replied disagree with the mean valve of 2.43, implying that not demonstration of experiments by the teachers during teaching science in school.

\section{Analysis of teachers' response on organization and facilities of science laboratories.}

Table 3. Analysis of teachers' response on organization and facilities of science laboratories.

\begin{tabular}{|c|c|c|c|c|}
\hline \multirow[t]{2}{*}{ No } & \multirow[t]{2}{*}{ Items } & & \multicolumn{2}{|c|}{ Teachers $=75$} \\
\hline & & & $\mathbf{N}$ & $\%$ \\
\hline \multirow[t]{3}{*}{1} & \multirow{3}{*}{$\begin{array}{l}\text { Is there a functional laboratory classroom with basic } \\
\text { laboratory tools and equipment in your school? }\end{array}$} & Yes & 23 & 30.66 \\
\hline & & No & 52 & 69.33 \\
\hline & & Total & 75 & 100 \\
\hline \multirow[t]{5}{*}{2} & \multirow{5}{*}{$\begin{array}{l}\text { How do you evaluate the availability of suitable } \\
\text { conditions and adequate materials for conducting } \\
\text { laboratory activities in your school? }\end{array}$} & Yes it complete & 2 & 2.6 \\
\hline & & Not satisfactory & 21 & 28 \\
\hline & & It is average & 3 & 4 \\
\hline & & Almost none & 49 & 65.3 \\
\hline & & Total & 75 & 100 \\
\hline \multirow[t]{6}{*}{3} & \multirow{6}{*}{$\begin{array}{l}\text { Do you believe on the idea that good science teaching } \\
\text { should be based on practical works such as } \\
\text { demonstration, experiments and project works, etc? }\end{array}$} & Strong agree & 45 & 60 \\
\hline & & Agree & 23 & 30.66 \\
\hline & & Undecided & 3 & 4 \\
\hline & & Disagree & 2 & 2.66 \\
\hline & & Strong disagree & 2 & 2.66 \\
\hline & & Total & 75 & 100 \\
\hline \multirow[t]{3}{*}{4} & \multirow{2}{*}{$\begin{array}{l}\text { Is in your school laboratory technician for biology, } \\
\text { physics and chemistry? }\end{array}$} & Yes & 5 & 6.66 \\
\hline & & No & 70 & 93.3 \\
\hline & & Total & 75 & 100 \\
\hline
\end{tabular}

As can be shown in table 3 item 1, 19(25.3\%) teacher respondents replied 'YES'. Whereas, 56(74.66\%) of students respondents replied 'NO' to the statement that there is functional laboratory classroom with basic laboratory tools and equipment.

As can be shown in table 3 item 2, $0(0 \%) \%$ ) of teacher respondents replied 'YES'. Whereas, 75(100\%) of students respondents replied ' $\mathrm{NO}$ ' to the statement that there are separate laboratory of science fields.

As can be shown in table 3 item 3,45(60\%) of teacher respondents replied strong agree 23(30.66\%) of teacher respondents replied agree; 3(4\%) of teacher respondents replied undecided; $12(16 \%)$ of teacher respondents replied disagree and 2(2.66) of teacher respondents replied strong disagree to the statement that good science teaching should be based on practical works such as demonstration, experiments and project works. Majority of respondents replied that strong agree and agree, implying that the most of teachers believed that the 
idea good science teaching should be based on practical works such as demonstration, experiments and project works

As can be shown in table 3 item 4, 5(6.66\%) of teacher respondents replied YES, whereas, $70(93.33 \%)$ of teacher respondents replied NO, implying that a few of laboratory technician biology, physics and chemistry exist in school.

3. Analysis of student response on organization and facilities of science laboratories

Table 4. Analysis of student response on organization and facilities of science laboratories

\begin{tabular}{|c|c|c|c|c|}
\hline \multirow[t]{2}{*}{ No } & \multirow[t]{2}{*}{ Items } & & \multicolumn{2}{|c|}{ students $=\mathbf{2 6 7}$} \\
\hline & & & $\mathbf{N}$ & $\%$ \\
\hline \multirow[t]{3}{*}{1} & Is there a functional laboratory classroom with basic & Yes & 69 & 25.84 \\
\hline & laboratory tools and equipment in your school? & No & 198 & 74.14 \\
\hline & & Total & 267 & 100 \\
\hline \multirow[t]{3}{*}{2} & If your response for question No. 1 is "yes", is there a & Yes, it is separate & 15 & 5.6 \\
\hline & separate laboratory room for science fields i.e. Biology, & No, it is combined. & 252 & 94.38 \\
\hline & Chemistry and Physics & Total & 267 & 100 \\
\hline \multirow[t]{6}{*}{3} & To what extent do you believe on the idea that good & Strong agree & 122 & 46 \\
\hline & science teaching should be based on practical works such & Agree & 120 & 44.94 \\
\hline & as demonstration, experiments and project works, etc? & Undecided & 5 & 1.87 \\
\hline & & Disagree & 15 & 5.6 \\
\hline & & Strong disagree & 5 & 1.87 \\
\hline & & Total & 267 & 100 \\
\hline \multirow[t]{3}{*}{4} & Is in your school laboratory technician for biology, & Yes & 20 & 7.49 \\
\hline & physics and chemistry? & No & 247 & 92.51 \\
\hline & & Total & 267 & 100 \\
\hline
\end{tabular}

As can be shown in table 4 item 1, 69(25.84\%) student respondents were replied YES; whereas, $198(74.14 \%)$ student respondents were replied NO to the statement that there is functional laboratory classroom with basic laboratory tools and equipment.

As can be shown in table 4 item 2, 15(5.6\%) of student respondents were replied YES, whereas, 252(94.34\%) students were replied No, to the statement that there is separate laboratory for of science fields.

As can be shown in table 4 item 3, 122(46\%), 120(44.94\%), 5(1.87\%), $15(5.6 \%)$ and 5(1.87\%) students replied strong agree, agree, undecided, disagree and strong disagree respectively to the statement that good science teaching should be based on practical works such as demonstration, experiments and project works. As can be seen from the data, majority of respondents replied that strong agree and agree, implying that the most of students believed that the idea good science teaching should be based on practical works such as demonstration, experiments and project works.

As can be shown in table 4 item 4, 20(9.36\%) of the students replied YES; whereas, 247(92.51\%) of the students replied NO. Thus, from this analysis it is possible to conclude that majority of respondents said No, which implying that there are few laboratory technician for biology, physics and chemistry in the school under the study.

4. Analysis of students and teachers response on organization and facilities of science laboratories Table 5. Analysis of students and teachers response on organization and facilities of science laboratories

\begin{tabular}{|c|c|c|c|c|c|c|c|}
\hline & Items & Participants & $\mathbf{N}$ & Mean & $\begin{array}{l}\text { Std. } \\
\text { Deviation }\end{array}$ & $\begin{array}{l}\text { Mean } \\
\text { Difference }\end{array}$ & $\begin{array}{l}\text { t- } \\
\text { Value }\end{array}$ \\
\hline \multirow[t]{2}{*}{1} & Is there a functional laboratory & Teachers & 75 & 3.98 & 1.03 & & \\
\hline & and equipment in your school? & Student & 267 & 3.61 & 1.14 & 0.37 & 2.63 \\
\hline \multirow[t]{2}{*}{2} & $\begin{array}{l}\text { To what extent do you believe that } \\
\text { learning science should be supported }\end{array}$ & Teachers & 75 & 3.78 & .85 & & 2.67 \\
\hline & with practical activities? & Student & 267 & 3.44 & 1.21 & 0.34 & \\
\hline \multirow[t]{2}{*}{3} & Is in your school laboratory technician & Teachers & 75 & 3.95 & .99 & & \\
\hline & for biology, physics and chemistry? & Student & 267 & 3.76 & 1.15 & 0.19 & 0.15 \\
\hline \multirow[t]{2}{*}{4} & Do Laboratory technicians and teachers & Teachers & 75 & 3.95 & .86 & 0.37 & 2.90 \\
\hline & activities? & Student & 267 & 3.58 & 1.24 & & \\
\hline
\end{tabular}


Table 5 items 1 illustrates that the teachers' and students' mean scores were 3.98 and 3.61 respectively, with mean difference of 0.37 . The t-test result with $\mathrm{p}$-value of $<0.05$ proves that there is no statistically significant difference between the two groups of respondents towards the item.

Table 5 items 2, the mean scores of the teachers and the students were 3.43 and 3.50 respectively, with mean difference of -0.07 . The computed t-test result with p-value of $0.63>0.05$ shows that the teacher respondents and student respondents do not significantly differ in their average ratings. This clearly indicated not the attention and commitment of teachers influenced on practical work implementation.

Table 5 item 3, the mean scores of teacher and student respondents were 3.78 and 3.44, with mean difference of 0.34 . The t-test result with p-value of $<0.05$ indicates that the two groups of respondents do not significantly differ in their average agreement towards the item. This shows that teachers and students believe that learning science should be supported with practical activities.

Table 5 items 4 indicated that the teachers' and students' mean scores were 3.95 and 3.58 respectively, with mean difference of 0.37 . The t-test result with $p$-value of $0.00<0.05$ proves that there is do not statistically significant difference between the two groups of respondents towards the item. This shows that laboratory technicians and teachers not get regular training on laboratory activities.

\section{Major constraints that obstacle practical works in secondary schools in Bale Zone Oromia}

According to the responses of students, teachers ,department heads, a few lab technicians and school principals, through written answers for open ended questions and interviews of the participants, the common constraints or problems facing the practical work activities in secondary schools are listed and identified simultaneously by all participants. One of the interview explained common known constraints of school practical work are the following

* No separate rooms for chemistry, biology and physics even if in some of school existed in one class.

* No attention to recruit laboratory technician experts beyond of government. Still now in many school a few practical work carry out by natural science teachers.

* Insufficient laboratory equipment, reagents and other facilities.

* Lack of teacher's commitment and low efficiency to carry out practical activities

* Lack of well-trained lab technicians/assistants and teachers as well.

* Lack of students' concern and awareness towards science practical works.

* Most government schools high teachers' workload per week around 20 and above

* The ignorance of practical examination in the assessment process and not giving credit for 1 practical activities.

\# Less attention and concern given to practical works by school managements and government as well.

* Shortage of time, especially large teachers work load in and plasma TV transmission in government schools.

$\$$ Deficit of budget or finance allocation.

\# Costs of laboratory equipment's and reagents become expensive and no access on the market.

* Another big problem in each science laboratory tasks in each page of student text enormous .so not balanced laboratory materials supply and student texts.

\section{Conclusions and Recommendations \\ Conclusions}

The main purpose of this research work is to investigate the present status of implementation of practical work in teaching -learning process in some selected secondary school of Bale Zone, Oromia. Hereafter, the following conclusions and recommendations were forwarded based on the findings of the study.

1. In the selected schools, the extent and frequency in which practical work implementation found in a very low level and it is poor and insufficient. The current study confirmed that there are schools without basic equipment's, reagents and other facilities and practical works in these schools are not carried out totally and the laboratories are dis-functional.

2. The inadequacy of laboratory equipment's, reagents and facilities, absence of separate lab rooms, lack of well-trained lab technicians and lack of commitment and interest of teachers are some of identified factors influencing quality implementation of science practical work.

3. In addition, absence of separate lab rooms and small sized laboratory rooms for the accommodation of all students of a large class; Lack of laboratory facilities, well trained teachers, and lab technicians; and Lack of attention and concern given to the practical works by school principals and government are also some of the impeding factors indented by the study.

\section{Recommendations}

Based on the finding of the study the following recommendations were forwarded. 
1. The introduction of practical examination in the students' assessment procedures of science results and the students that carry out practical activities should be credited and it has to be added to the total science scores of the student.

2. School managements, teachers, the community and the government at large must give consideration to the capacity building of the schools in terms of finance and training. So, schools would be able to prepare laboratories with basic facilities, carrying out project works, field trips in order to produce highly qualified, skillful and creative personnel.

3. The curriculum designers should give emphasis to the practical works of science subjects in relation to the assessment techniques, the time allocation for conducting practical works, the class size, training systems of teachers and technicians, standard of practical activities, realizing 70:30 student ratio of natural science to social science and Humanities, etc to students future promising of successful endeavor and sustainable development of the country.

4. Developing team works of teachers in each science subject to carry out a preliminary experiments and demonstrations before participating students in practical works. Preparation of separate manuals for Biology, chemistry and Physics subjects. Scheduling a regular time table for implementation of practical activities, planning to monitor and evaluate performances of teachers and students every quarter or every semester. 5. Inviting other researchers for further investigation on practical activities to come up with new

\section{References}

Austin (2016). The perspective of pragmatism and their types Procedia Soc. Behav. Sci.,

Aklilu Yilma (2010), The implementation of Biology practical work in selected general secondary schools in East Wollega zone of Oromia region, Addis Ababa, AAU

Bednar, k. (1991).Constructivism learning theory. saskatchewan :pressing press.

Bekalo S. A. and Welford A.G. (1999), International Journal of Science Education VOL.21,

Bekalo S.A (1997), Factors influencing the place and development or Practical work in secondar science, the case of Ethiopia, (Unpublished Ph.D Thesis).

Chaudhry S.S, Sharma A.P. \&Hooda H.C. (1975), New Practical physics (4thedition).

Cress Well, J. (2003).Research Design, Quantitative, Qualitative and Mixed Approaches London: Sage printing press

EMA, (2002).Foundation for modern science teaching. Addis Ababa: Ministry of Education.

Gurney, P.(2008).Five Factors for Effective Teaching.New Zealand Journal of TeacWork. Vol. 4,Issue 2, pp. 8998.

Guskey, T. R. (2000). Evaluating Professional Development. London: Sage.

Husen T. and Postehwaite T.N. (1994), The International Encyclopedia of Education ( $2{ }^{\text {nd }}$ edition), Great Britain, BPC Wheaton Ltd, Exeter, Vol. 1

Holbrook, J. and M. Rannikmae,( 2007). The nature of science education for enhancing scientific literacy. Int. J. Sci. Educ., 9

Kerdin (2003), Practical work in school science, Bangladesh and Wales, Leicester

Kiflu (2015) Assessment of laboratory practices in teaching grade 8 (eight) chemistry in some selected upper primary schools of Yeka Sub-City of Addis Ababa city Administration,

Lunetta VN (2003). The Laboratory in Science Education: Foundations for the Twenty- First Century. Science Education.The Pennsylvania State University, University Park

Lunetta VN (2004). The laboratory in science education: foundation for the 21st century.Sci. Educ. University press.

Maleque, A. (2007). Shikkha Bigyan O Bangladesha Shikkha .Bangladesh: The University Grants Commission of Bangladesh.

Moe,(2015).education system of Kenya. kenya: publishing press.

Moe,(2013).education system of Australia country. australia: publishing press.

Moe.(2011).Education system in Bangladesh Education structure. Bangladesh: pressing press

MoE,( 2004).national strategy of practical work in science. Ethiopia: pressing press

Mohamed, Z. (2008). Teacher training of secondary school physics teachers. Malaysia: Critical issues and a new direction.

Ogborn, J. (2001).Explaining Science in the Classroom. Buckingham: Open University Press

Parawira, W. (2009).Achievement of the sustainable development goals. Zimbabuwe: press

Robin, M.(2004).Role and Vision, Nationa Academy of Sciences. Washington: pressing Press

Rickinso,M.(2004).A review of research on outdoor learning. Shropshire UK: Field Studies Council

Rita .H (2009) Elementary Teachers Attitudes Towards Science and the Teaching of Science and Technology wongiton univrsity press 
Shaila, B. (2011).The role of practical work in teaching and learning. Bangladish: Pressingpress

Tesfaye, A.(2009).Status of Physics practical work implementation, the case of some Selected government and private secondary schools in Addis Ababa city Administration. Addis Ababa: AAU

Tolessa,D.(2016). Factors Affecting Implementation of Practical Activities in Science education. Ethiopia: pressing press

Tsegaye, E. (2012).The status of practical work in science teaching.Addis Ababa: AAU press

Zinaye T. and Dawit M. (2001), Teaching High School Physics, Teaching material, Bahirdar, Bahirdar University. 